\title{
Clinical characteristics of malignant melanoma in central China and predictors of metastasis
}

\author{
KE SHI $^{1}$, XURAN ZHU ${ }^{1}$, ZHONGYANG LIU $^{1}$, NAN SUN ${ }^{1}$, LUOSHA GU ${ }^{1}$, YANG WEI ${ }^{1}$, XU CHENG $^{1}$, \\ ZEWEI ZHANG ${ }^{1}$, BAIHUI XIE ${ }^{1}$, SHUAIXI YANG ${ }^{2}$, GUANGSHUAI LI ${ }^{1}$ and LINBO LIU ${ }^{1}$ \\ Departments of ${ }^{1}$ Plastic Surgery and ${ }^{2}$ Anorectal Surgery, The First Affiliated Hospital of Zhengzhou University, \\ Zhengzhou, Henan 450052, P.R. China
}

Received November 5, 2018; Accepted November 13, 2019

DOI: $10.3892 / \mathrm{ol} .2019 .11219$

\begin{abstract}
Cutaneous malignant melanoma (MM) is the most malignant type of all skin neoplasms. There is wide variability in the characteristics of MM between patients of different races. The aim of the present study was to investigate the clinicopathological characteristics of patients with MM in central China and to assess the value of specific hematological and biochemical indices for predicting metastasis. The data of 167 patients with MM from the First Affiliated Hospital of Zhengzhou University (Henan, China) were retrospectively analyzed and compared with the data of patients with MM available from cBioPortal for Cancer Genomics. Following analysis of the clinicopathological characteristics of the 167 patients, the median overall survival time was 50 months, and the median disease-free survival time was 35 months. Albumin/D-dimer prognosis score (ADPS), lactate dehydrogenase, sex, T stage, tumor-node-metastasis stage, Breslow thickness, Clark level, histological type, growth phase, ulceration and metastasis were all significantly associated with prognosis. An ADPS of <341.01 was identified as an independent predictor of metastasis. The trial registration no. is 2018-LW-037 and this clinical trial was registered in the First Affiliated Hospital of Zhengzhou University Clinical Trial Registry in March 1, 2018.
\end{abstract}

Correspondence to: Dr Linbo Liu or Dr Guangshuai Li, Department of Plastic Surgery, The First Affiliated Hospital of Zhengzhou University, Building 2, 1 Jianshe East Road, Zhengzhou, Henan 450052, P.R. China

E-mail: liulinbo@zzu.edu.cn

E-mail: liguangshuai@zzu.edu.cn

Abbreviations: OS, overall survival; DFS, disease free survival; MM, malignant melanoma; LDH, lactate dehydrogenase; ADPS, serum albumin/D-dimer prognosis score; PDPS, serum prealbumin/ D-dimer prognosis score; AUC, area under the curve; HR, hazard ratio; $\mathrm{CI}$, confidence interval.

Key words: MM, metastasis, albumin/D-dimer, prognosis, cBioPortal

\section{Introduction}

Malignant melanoma (MM) is a highly aggressive cancer derived from neural crest melanocytes and occurs most frequently in the skin, digestive tract, eyes, genitals and nasal cavity (1-3) The prognosis of patients with MM is poor and the 5-year survival is reported to be $<20 \%$ (4). Each year, $\sim 20,000$ cases of cutaneous MM are reported in China and the incidence is growing by $3-5 \%$ per year (5). The incidence of MM is lower in China compared with Western countries, but survival is shorter in Chinese patients $(6,7)$. In addition, differences in incidence, etiology and clinical characteristics between different races are still poorly understood.

The development of prognostic markers of MM, such as serum lactic dehydrogenase (LDH) and the identification of new treatment targets; for example, melanogenesis, have improved the treatments available for patients and patient outcomes $(8,9)$. Serum LDH appears to be an independent marker of stage IV MM and studies have suggested that serum LDH may be used to identify patients requiring complete mastectomy $(1,2)$. However, to the best of our knowledge, it is unclear whether serum LDH can be used to predict the metastatic possibility in the early stages of MM.

In the present study, the prognostic value of commonly tested hematological and biochemical parameters were investigated, including serum albumin and prealbumin, $\mathrm{LDH}$, total leukocyte count and serum D-dimer levels, a degradation product of fibrinolysis. In addition, the albumin/D-dimer ratio [serum albumin/D-dimer prognosis score (ADPS)] and the serum prealbumin/D-dimer ratio [serum prealbumin/D-dimer prognosis score (PDPS)] were determined. Serum albumin (10) and prealbumin levels (11) reflect the nutritional and inflammatory status of the patient. Malnourished patients with cancer often have poor immune function, drug tolerance and poor response to treatments (12). D-dimer has been found to be associated with malignancy and D-dimer levels are associated with tumor stage, tumor prognosis, lymph node involvement and survival of patients with several types of cancer, including esophageal squamous cell carcinoma (13), gastric cancer (14), breast cancer (15), colorectal cancer (16), lung cancer (17) and ovarian cancer (18). Moreover, cancer-associated inflammation is an important contributor to disease progression and survival, and systemic inflammation is associated with 
alterations in peripheral blood leukocytes (19). Therefore, in the present study, it was hypothesized that a combination of D-dimer levels, leukocyte count and albumin or prealbumin levels may be useful for predicting prognosis of patients with MM.

The aim of the present study was: i) To explore the characteristics of $\mathrm{MM}$ and the factors affecting prognosis in Chinese patients with MM; ii) analyze the similarities and differences in characteristics with patients with MM from other regions of the world; and iii) to determine the value of commonly tested hematological and biochemical parameters for predicting metastasis in patients with MM.

\section{Patients and methods}

Patients. The present study was approved by The Ethics Committee of the First Affiliated Hospital of Zhengzhou University (Zhengzhou, China; trial registration no. 2018-LW-037). Written informed consent was obtained from all participants included in the study. A total of 176 patients at the First Affiliated Hospital of Zhengzhou University were collected. Patients with a history of other malignancies, autoimmune disease, chronic renal or hepatic disease, diabetes, thyroid disorders and taking anti-inflammatory drugs were excluded. A total of 167 patients were included in this study, including 74 men (44.3\%) and 93 women (55.7\%). All patients were diagnosed with cutaneous or mucosal MM according to the criteria of the American Joint Committee on Cancer, 8th edition (1) between April 2003 and April 2018. The age range of all patients was 22-92 years and the median age was 56.81 years. The demographic and clinical data of these patients was obtained from medical records for analysis; including personal data (age at diagnosis, sex, living habits, family history); blood test results (serum albumin and prealbumin, serum LDH, total leukocyte count, serum D-dimer); tumor-related data [tumor location and stage, presence of metastasis, Breslow level (20), Clark level (3), presence of ulceration]; treatment received (adjuvant therapy and type of surgery) and follow-up data (current status, survival). Table I summarizes the collected data.

cBioPortal. The characteristics of the patients of the present study were compared with patients around the world registered in the cBioPortal for Cancer Genomics (cbioportal.org). cBioPortal combines a number of large-scale cancer genomics projects, including The Cancer Genome Atlas (https://www.cancer. gov/tcga) and The International Cancer Genome Consortium (https://icgc.org/), and catalogues data on genetic, epigenetic, gene expression and proteomic events. The portal also provides graphical summaries of gene-level data from multiple platforms, network visualization and analyses, survival analysis (21) patient-centric queries and software programmatic access (2). cBioPortal contained 12 studies with a total of 1,566 patients, focusing on melanoma of eye and skin (Table II). Following elimination of duplicate data, a total of 1,518 patients remained, including 97\% of Caucasian patients from America and Europe and $3 \%$ of Asian or African patients (Fig. 1A).

Statistical analysis. Data were analyzed using Microsoft Excel 2007 (Microsoft Corporation), SPSS version 20.0 (IBM Corp.) and GraphPad Prism version 5 (GraphPad
Software Inc.). Quantitative variables were presented as either mean \pm standard deviation or median and interquartile range, depending on the normality of the distribution. Normally distributed quantitative variables were analyzed using a Student's t test, data with unequal variance were analyzed using a Welch's t-test. Non-normally distributed continuous data were compared using a Mann-Whitney U test. Qualitative variables were reported as frequencies and percentages and compared using a $\chi^{2}$ test or the Fisher's exact test. Receiver operating characteristic (ROC) analysis was used to identify the ideal cutoff value of ADPS for distinguishing between patients with and without metastasis. The Youden index [(specificity + sensitivity)-1] was calculated as a measure of overall efficacy. The area under curve (AUC) was used to assess the predictive value of ADPS, serum prealbumin/D-dimer prognosis score (PDPS) and D-dimer. Regression tree analysis was used to measure the sensitivity, specificity and accuracy of the indicator for predicting metastasis in patients with MM. Variables that were significantly associated with tumor metastasis were analyzed using multivariate Cox regression analysis to identify independent predictors of metastasis. Kaplan-Meier curves were constructed for survival analysis and a log-rank test was used to determine the differences in survival rate. In Kaplan-Meier survival analysis of prognostic factors for OS, the prognostic factors with multigroups in $\mathrm{T}$ stage, TNM stage, Breslow thickness, Clark level, histological type and anatomic region were analyzed by pooled over strata in log-rank test. $\mathrm{P}<0.05$ was considered to indicate a statistically significant difference. In the comparison of MM patients with and without metastasis, each numerical data was limited by the mean difference and divided into higher group and lower group. Regarding other statistic analyses, MM patients were divided into low or high group according to the ADPS value (341.01), the ideal cutoff value by ROC analysis, whereas other quantitative data were grouped by mean value.

\section{Results}

Clinical characteristics of patients with MM. A total of 85 patients $(50.9 \%)$ were still alive at the end of the study whereas 82 patients (49.1\%) had died. Median overall survival (OS) was 50 months (range, 0-181 months; Fig. 1C) and median disease-free survival (DFS) was 35 months (range, 0-124 months; Fig. 1D). The proportion of patients with tumor node metastasis (TNM) stage I/II, III or IV were $64 / 167$ (38.3\%), 38/167 (22.8\%) and 65/167 (38.9\%), respectively. Data on Breslow thickness were available for 137 patients; the Breslow thickness was $<1 \mathrm{~mm}$ in $42 / 137$ patients $(30.7 \%)$, $1.01-2.00 \mathrm{~mm}$ in $48 / 137$ patients $(35.0 \%), 2.01-4.00 \mathrm{~mm}$ in $27 / 137$ patients $(19.7 \%)$ and $>4.00 \mathrm{~mm}$ in $20 / 137$ patients (14.6\%). Data on the Clark level were available for 138 patients; $30 / 138$ patients (21.7) were classed as level 1,34/138 patients (21.7\%) were classed as level 2, 41/138 patients (29.7\%) were classed as level $3,16 / 138$ patients (11.6\%) were classed as level 4 and 17/138 patients (12.3\%) were classed as level 5. The primary lesion was on the trunk in $21 / 167$ patients $(12.6 \%)$, in the head/neck region in $14 / 167$ patients $(8.4 \%)$, in the extremities in $97 / 167$ patients $(58.1 \%)$, in the mucosa in $24 / 167$ patients 
Table I. Clinicopathological characteristics of patients with MM from the experimental cohort.

$\begin{array}{ccc}\text { Variable } & \text { Mean } \pm \text { standard } \\ \text { deviation/proportion, \% }\end{array}$

\begin{tabular}{lrc}
\hline OS, months & 167 & $35.9 \pm 31.6$ \\
DFS, months & 167 & $26.9 \pm 28.8$ \\
Age, years & 167 & $56.8 \pm 15.0$ \\
$\leq 40$ & 23 & $13.8 \%$ \\
$40-50$ & 39 & $22.7 \%$ \\
$50-60$ & 33 & $20.4 \%$ \\
$60-70$ & 44 & $26.3 \%$ \\
$70-80$ & 20 & $12.0 \%$ \\
$>80$ & 8 & $4.8 \%$ \\
Sex & 167 &
\end{tabular}

Male 74

Female 93

Overall survival status $\quad 167$

Alive 85

Deceased

82

Family history of tumor 167

Yes

No

Unknown

T stage

pT0

pT1

pT2

pT3

pT4

TNM stage

I or II

III

IV

$44.3 \%$

$55.7 \%$

$50.9 \%$

$49.1 \%$

$14.4 \%$

$58.1 \%$

$27.5 \%$

167

13

42

57

36

19

167

64

38

65

Breslow, mm

$\leq 1.00$

1.01-2.00

2.01-4.00

$>4.00$

137

42

48

27

20

Clark

138

1

2

3

4

5

Histological type

ALM
NM
SSM
LMM
MCM
Unclassifiable
Growth phase
Radial
Vertical

Vertical

$30.7 \%$

$35.0 \%$

$19.7 \%$

$14.6 \%$

$21.7 \%$

$24.6 \%$

$29.7 \%$

$11.6 \%$

$12.3 \%$

$13.8 \%$

$22.7 \%$

$20.4 \%$

$26.3 \%$

$12.0 \%$

$4.8 \%$
Table I. Continued. Clinicopathological characteristics of patients with MM from the experimental cohort.

\begin{tabular}{|c|c|c|}
\hline Variable & $\mathrm{n}$ & $\begin{array}{c}\text { Mean } \pm \text { standard } \\
\text { deviation/proportion, } \%\end{array}$ \\
\hline Anatomic region & 167 & \\
\hline Trunk & 21 & $12.6 \%$ \\
\hline Head/neck & 14 & $8.4 \%$ \\
\hline Extremities & 97 & $58.1 \%$ \\
\hline Mucosal & 24 & $14.4 \%$ \\
\hline Unknown & 11 & $6.6 \%$ \\
\hline Ulceration & 147 & \\
\hline With & 88 & $52.7 \%$ \\
\hline Without & 59 & $35.3 \%$ \\
\hline Unknown & 20 & $13.0 \%$ \\
\hline \multicolumn{3}{|l|}{ Metastasis } \\
\hline With & 104 & $62.3 \%$ \\
\hline Without & 63 & $37.7 \%$ \\
\hline Therapy & 167 & \\
\hline Surgery & 59 & $35.3 \%$ \\
\hline $\begin{array}{l}\text { Adjuvant therapy } \\
\text { without surgery }\end{array}$ & 14 & $8.4 \%$ \\
\hline $\begin{array}{l}\text { Adjuvant therapy } \\
\text { with surgery }\end{array}$ & 88 & $52.7 \%$ \\
\hline Without therapy & 6 & $3.6 \%$ \\
\hline Albumin, g/l & 109 & $42.83 \pm 3.32$ \\
\hline Prealbumin, mg/l & 100 & $244.60 \pm 54.26$ \\
\hline D-dimer, ug/l & 105 & $0.208 \pm 0.209$ \\
\hline Leukocyte $10^{9} / 1$ & 113 & $6.56 \pm 2.17$ \\
\hline LDH, U/1 & 96 & $183.78 \pm 55.54$ \\
\hline
\end{tabular}

T0, no evidence of primary tumor; OS, overall survival; DFS, disease free survival; T, tumor; TNM, tumor node metastasis; ALM, acral lentiginous melanoma; MCM, mucosal melanoma; NM, nodular melanoma; SSM, superficial spreading melanoma; LMM, lentigo malignant melanoma; LDH, lactate dehydrogenase.
$(37.8 \%)$ and at unknown locations in $11 / 167$ patients $(6.6 \%)$. Ulcerative melanoma was observed in 88 out of 167 patients $(52.7 \%)$ and nonulcerative melanoma was observed in 59 out of 167 patients $(35.3 \%)$. The mean total serum Albumin, D-dimer and LDH were 42.83 $\pm 3.32 \mathrm{~g} / 1,0.208 \pm 0.209 \mathrm{ug} / \mathrm{l}$ and $183.78 \pm 55.54 \mathrm{U} / 1$, respectively. The clinicopathological characteristics of patients and results of blood tests are described in Table I.

Comparison of characteristics of Chinese patients with MM with the cBioPortal data. The proportion of male patients was higher in the cBioPortal cohort than in the experimental cohort (61\% vs. 44\%; Fig. 1Fa and Fb). Age at diagnosis of patients with MM ranged from 40-70 years in both the cBioPortal cohort and in experimental cohort (Fig. 1Ba and $\mathrm{Bb}$ ). MM was most commonly diagnosed in patients aged 50-60 years in the cBioPortal cohort (Fig. 1Ba); whereas, in the experimental cohort MM was most commonly diagnosed in patients aged 
Table II. Results of tumor type and number of cases from cBioPortal.

\begin{tabular}{|c|c|c|c|c|}
\hline Author, year & Source & Cancer type & $\begin{array}{l}\text { No. of } \\
\text { cases }\end{array}$ & (Refs.) \\
\hline $\begin{array}{l}\text { Taylor et al, 2018; } \\
\text { Sanchez-Vega et al, 2018; } \\
\text { Liu et al, 2018; } \\
\text { Hoadley et al, 2018; } \\
\text { Gao et al, 2018; } \\
\text { Ellrott et al, } 2018\end{array}$ & TCGA, PanCancer Atlas & Uveal melanoma & 80 & $(42-47)$ \\
\hline 2018 & TCGA, provisional $^{\mathrm{a}}$ & Uveal melanoma & 80 & \\
\hline Liang et al, 2017 & TGEN, genome research, 2017 & $\begin{array}{l}\text { Paired-exome sequencing of acral } \\
\text { melanoma }\end{array}$ & 38 & $(48)$ \\
\hline Berger et al, 2012 & Broad/Dana Farber, nature 2012 & Cutaneous melanoma & 26 & (49) \\
\hline 2017 & $\begin{array}{l}\text { MSKCC, JCO precision } \\
\text { oncology, } 2017^{\mathrm{b}}\end{array}$ & $\begin{array}{l}\text { Next generation sequencing (NGS) } \\
\text { of pre-treatment metastatic } \\
\text { melanoma samples }\end{array}$ & 66 & \\
\hline Hodis et al, 2012 & Broad, cell, 2012 & Skin cutaneous melanoma & 121 & $(50)$ \\
\hline $\begin{array}{l}\text { Taylor et al, 2018; } \\
\text { Sanchez-Vega et al, 2018; } \\
\text { Liu et al, 2018; } \\
\text { Hoadley et al, 2018; } \\
\text { Gao et al, 2018; } \\
\text { Ellrott et al, } 2018\end{array}$ & TCGA, PanCancer Alas & Skin cutaneous melanoma & 448 & $(42-47)$ \\
\hline 2018 & TCGA, provisional & Skin cutaneous melanoma ${ }^{a}$ & 479 & \\
\hline Krauthammer et al, 2012 & Yale, nat genet 2012 & Skin cutaneous melanoma & 91 & $(51)$ \\
\hline Van Allen et al, 2014 & Broad, cancer discov 2014 & Skin cutaneous melanoma & 78 & $(52)$ \\
\hline Hugo et al, 2016 & UCLA, cell 2016 & $\begin{array}{l}\text { Whole-exome sequences of } \\
\text { pretreatment melanoma tumors }\end{array}$ & 39 & $(53)$ \\
\hline Shain et al, 2015 & Broad institute, nat genet 2015 & Desmoplastic melanoma & 20 & (54) \\
\hline
\end{tabular}

60-70 years (Fig. 1Bb). Median OS was 66.43 months (range, 0.36-369.65 months) in the cBioPortal cohort vs. 50 months (range, 0-181 months) in the experimental cohort. Median DFS was 49.21 months (range, 0.46-386.50 months) in the cBioPortal cohort vs. 35 months (range, 0-112 months) in experimental cohort. The 3-, 5- and 10-year survival rates were 59.1, 47.7 and $31.6 \%$, respectively, in the cBioPortal cohort vs. 59.0, 43.0 and $13.5 \%$ in the experimental cohort (Fig. 1C and D). OS was $47 \%$ in the cBioPortal cohort vs. $49 \%$ in experimental cohort (Fig. 1E). In the cBioPortal cohort, the most common locations of melanoma were the trunk $(54 \%)$, followed by the extremities (22\%), head and neck (16\%) and mucosa (5\%) (Fig. 1Ga), whereas in the experimental cohort the most common locations of melanoma were the extremities $(58.1 \%)$, followed by the mucosa (14\%) and the trunk (13\%) (Fig. 1Gb). The reasons for these differences remain unclear; however, a possible explanation may be due to differences in lifestyle factors.

Melanoma treatment. Patients in the experimental cohort received a variety of treatments, including combinations of surgery, chemotherapy, immunotherapy and biotherapy. A total of $88 / 167$ patients $(52.7 \%)$ received surgery and adjuvant therapy, whereas 59/167 patients $(35.3 \%)$ received only surgery and 14/167 patients (8.4\%) received only adjuvant therapy (Fig. 2); treatment details were not available for $6 / 167$ (3.6\%) patients (Table I). Treatment selection for the patients in the experimental cohort was in accordance with the 1st edition of Consensus on the Diagnosis and Treatment of Melanoma in China (August, 2008) (1). Chemotherapeutic agents used included Taxol, Dacarbazine and platinum-type drugs. Immunotherapeutic agents used included thymopentin, and recombinant human interferon $\mathrm{g}$ and/or interleukin-2. There were a total of 15 different combinations of treatments; the most common treatment was surgery alone, followed by surgery plus immunotherapy and then surgery plus bioimmunotherapy (Fig. 2).

Comparison of patients with and without metastasis. The experimental patients were separated into two groups: Patients with metastasis $(n=104)$ and those without metastasis $(n=63)$. Mean serum albumin $(\mathrm{P}=0.145)$, prealbumin $(\mathrm{P}=0.752), \mathrm{LDH}$ $(\mathrm{P}=0.150)$ and leukocyte count $(\mathrm{P}=0.224)$ did not significantly differ between the two groups. However, patients with metastasis had significantly higher D-dimer levels $(0.237 \pm 0.217 \mu \mathrm{g} / 1$ vs. $0.151 \pm 0.134 \mu \mathrm{g} / \mathrm{l} ; \mathrm{P}<0.001)$, and a significantly lower 

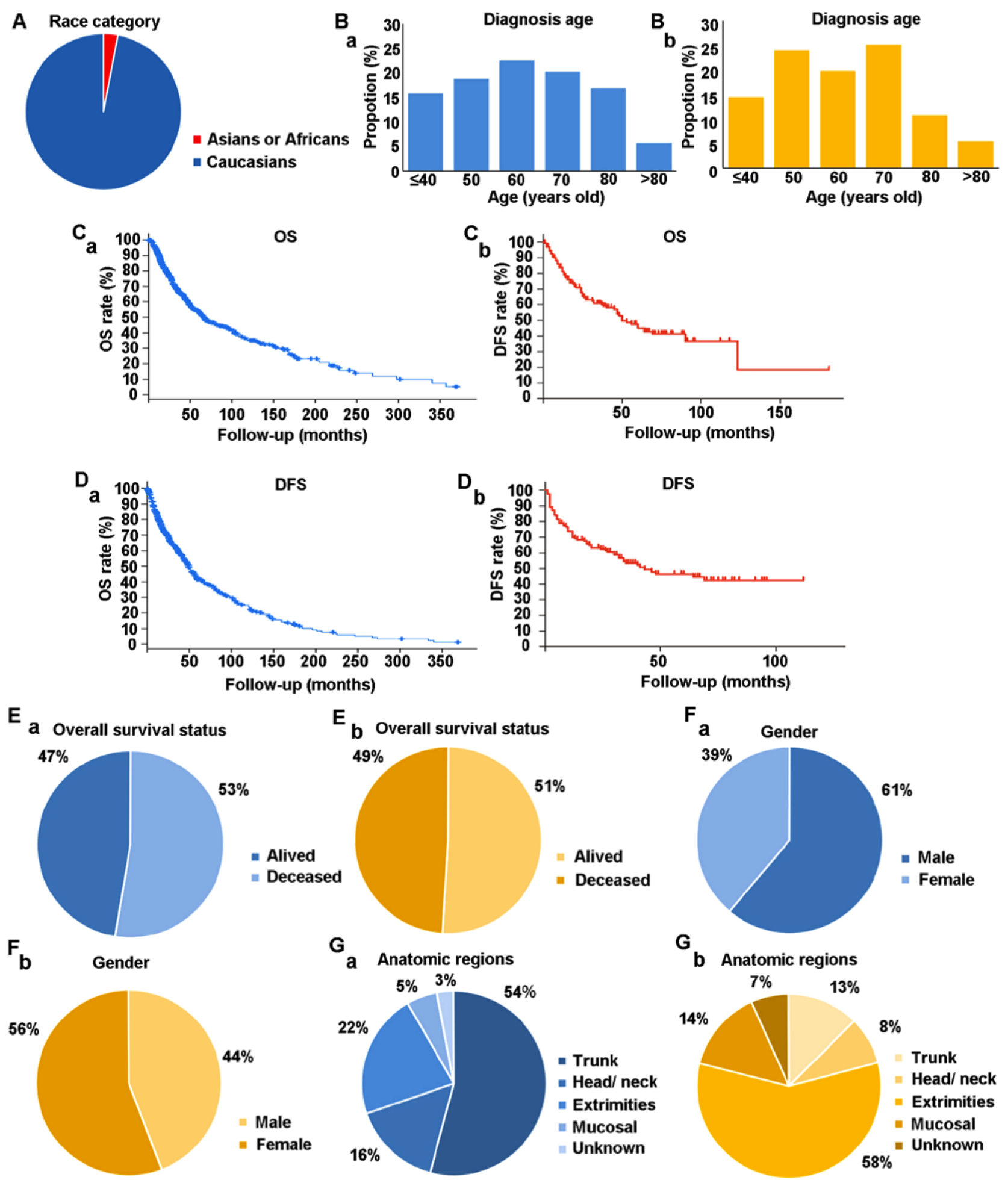

$E_{\text {b }}$ Overall survival status $49 \%$

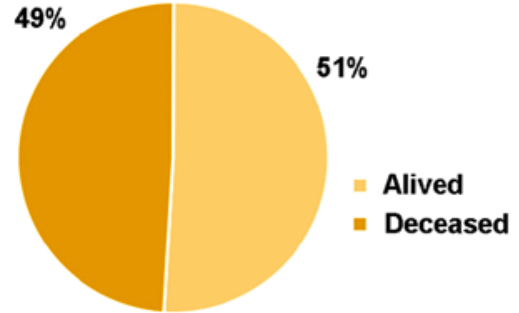

G

a Anatomic regions

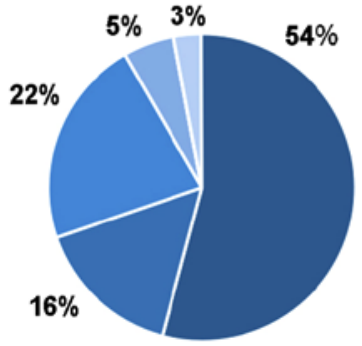

$F$

F Gender

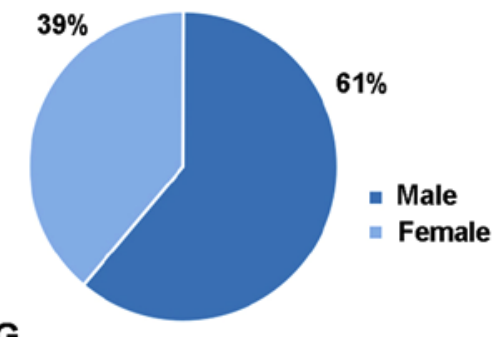

G

b Anatomic regions

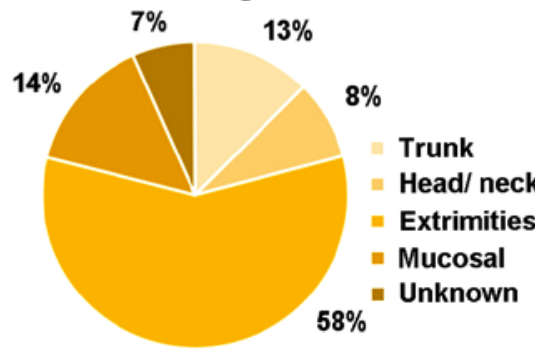

Figure 1. Comparison of clinical characteristics between the cBioPortal cohort and the experimental cohort. (A) Categorization of patients in cBioPortal by race. ( $\mathrm{Ba}$ ) Categorization of patients in cBioPortal by age. (Bb) Categorization of patients in the experimental cohort by age at diagnosis. (Ca) OS from cBioPortal. (Cb) OS of experimental cohort. (Da) DFS from cBioPortal. (Db) DFS from the experimental cohort. (Ea) Overall survival status from cBioPortal cohort. (Eb) OS from the experimental cohort. (Fa) Sex of patients from the cBioPortal cohort. (Fb) Sex of patients from the experimental cohort. (Ga) Anatomic regions of MM for patients with MM of the cBioPortal cohort. (Gb) Anatomic regions of MM for patients with MM of the experimental cohort. OS, overall survival; DFS, disease free survival; MM, malignant melanoma.

ADPS (328.61 \pm 235.72 vs. $452.46 \pm 302.07$; $\mathrm{P}<0.001)$ and PDPS $(1,913.53 \pm 1,464.42$ vs. $2,657.75 \pm 1,983.42 ; \mathrm{P}<0.05)$ (Table III).

ROC analysis. ROC analysis showed an ADPS of 341.01 to be the ideal cutoff value for differentiating between patients with and without metastasis and the AUC for ADPS was 0.773 (Fig. 3). For prediction of metastasis, ADPS had $93.8 \%$ sensitivity, 59.6\% specificity, 54.6\% accuracy and a Youden index of $53.40 \%$. The AUC for PDPS was 0.547 . For prediction of metastasis, PDPS had $31.3 \%$ sensitivity, $84.7 \%$ specificity, 
Table III. Comparison between experimental cohort patients with and without metastatic MM.

\begin{tabular}{|c|c|c|c|}
\hline Variable & $\begin{array}{l}\text { Metastatic, } \\
\text { mean } \pm \mathrm{SD}\end{array}$ & $\begin{array}{c}\text { Non-metastatic }{ }^{\mathrm{h}} \\
\text { mean } \pm \mathrm{SD} \text { or mean }(\mathrm{n}=\%)\end{array}$ & P-value \\
\hline Albumin, $g / l^{\mathrm{d}}$ & $42.12 \pm 4.35$ & $42.99 \pm 2.90$ & 0.145 \\
\hline Prealbumin, $\mathrm{mg} / \mathrm{l}^{\mathrm{e}}$ & $246.90 \pm 57.58$ & $243.70 \pm 50.70$ & 0.752 \\
\hline $\mathrm{LDH}, \mathrm{U} / \mathrm{l}^{\mathrm{f}}$ & $191.43 \pm 59.86$ & $176.56 \pm 37.22$ & 0.150 \\
\hline D-dimer, ug/lf & $0.43 \pm 0.85$ & $0.16 \pm 0.13$ & $<0.001$ \\
\hline Leukocyte, $10^{9} / 1^{\mathrm{f}}$ & $6.77 \pm 4.58$ & $5.93 \pm 1.97$ & 0.224 \\
\hline ADPS $^{f}$ & $290.46 \pm 241.84$ & $434.35 \pm 276.99$ & $<0.001$ \\
\hline PDPS $^{\mathrm{e}}$ & $1,789.50 \pm 1,449.42$ & $2,521.04 \pm 1,809.78$ & $0.018^{\mathrm{a}}$ \\
\hline Sex & & & $<0.001^{\mathrm{c}}$ \\
\hline Male & $57(54.8 \%)$ & $17(25.8 \%)$ & \\
\hline Female & $47(45.2 \%)$ & $49(74.2 \%)$ & \\
\hline Breslow $^{\mathrm{g}}$ & & & $<0.001^{\mathrm{c}}$ \\
\hline$\leq 1.00$ & $12(16.0 \%)$ & $29(50.0 \%)$ & \\
\hline $1.01-2.00$ & $28(37.3 \%)$ & $19(32.8 \%)$ & \\
\hline $2.01-4.00$ & $18(24.0 \%)$ & $8(13.8 \%)$ & \\
\hline$>4.00$ & $17(22.7 \%)$ & $2(3.4 \%)$ & \\
\hline Clark level $^{\mathrm{g}}$ & & & $<0.010^{\mathrm{a}}$ \\
\hline 1 & $12(16.0 \%)$ & $17(29.8 \%)$ & \\
\hline 2 & $14(18.7 \%)$ & $19(33.3 \%)$ & \\
\hline 3 & $25(33.3 \%)$ & $15(26.3 \%)$ & \\
\hline 4 & $11(14.7 \%)$ & $4(7.0 \%)$ & \\
\hline 5 & $13(17.3 \%)$ & $2(3.5 \%)$ & \\
\hline Anatomic region $^{g}$ & & & 0.078 \\
\hline Truck & $16(17.0 \%)$ & $5(7.9 \%)$ & \\
\hline Head/neck & $10(10.6 \%)$ & $4(6.3 \%)$ & \\
\hline Extremities & $51(54.3 \%)$ & $47(74.6 \%)$ & \\
\hline Mucosal & $7(18.1 \%)$ & $7(11.1 \%)$ & \\
\hline Ulceration $^{\mathrm{g}}$ & & & $<0.001^{\mathrm{c}}$ \\
\hline With & $69(80.2 \%)$ & $19(31.1 \%)$ & \\
\hline Without & $17(19.8 \%)$ & $42(68.9 \%)$ & \\
\hline T stage ${ }^{g}$ & & & $0.003^{\mathrm{b}}$ \\
\hline pT0 & $13(7.8 \%)$ & $0(0)$ & \\
\hline pT1 & $11(6.6 \%)$ & $31(18.6 \%)$ & \\
\hline pT2 & $38(22.8 \%)$ & $19(11.4 \%)$ & \\
\hline pT3 & $25(15.0 \%)$ & $11(6.6 \%)$ & \\
\hline pT4 & $17(10.2 \%)$ & $2(1.2 \%)$ & \\
\hline Histological type ${ }^{\mathrm{g}}$ & & & $<0.001^{\mathrm{c}}$ \\
\hline ALM & $21(13.5 \%)$ & $31(20.0 \%)$ & \\
\hline NM & $23(14.8 \%)$ & $1(0.6 \%)$ & \\
\hline SSM & $17(11.0 \%)$ & $16(10.3 \%)$ & \\
\hline LMM & $14(9.0 \%)$ & $8(5.1 \%)$ & \\
\hline MCM & $17(11.0 \%)$ & $7(4.5 \%)$ & \\
\hline Growth phase ${ }^{g}$ & & & $<0.001^{\mathrm{c}}$ \\
\hline Radial & $15(20.3 \%)$ & $46(82.1 \%)$ & \\
\hline Vertical & $59(79.7 \%)$ & $10(17.9 \%)$ & \\
\hline
\end{tabular}

${ }^{\mathrm{a} P}<0.05,{ }^{\mathrm{b}} \mathrm{P}<0.01,{ }^{\mathrm{c}} \mathrm{P}<0.001 .{ }^{\mathrm{d}}$ Mean $\pm \mathrm{SD}, \mathrm{P}$-value based on Welch's t-test; ${ }^{\mathrm{e}}$ Mean $\pm \mathrm{SD}, \mathrm{P}$-value based on Student's t-test; ${ }^{\mathrm{f}} \mathrm{Mean} \pm \mathrm{SD}, \mathrm{P}$-value

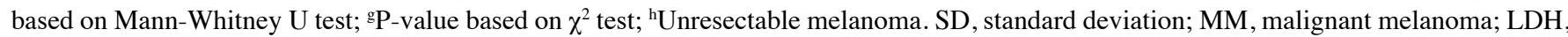
lactate dehydrogenase; ADPS, serum albumin/D-dimer prognosis score; PDPS, serum prealbumin/D-dimer prognosis score; T, tumor; ALM, acral lentiginous melanoma; NM, nodular melanoma; SSM, superficial spreading melanoma; LMM, lentigo malignant melanoma; MCM, mucosal melanoma. 


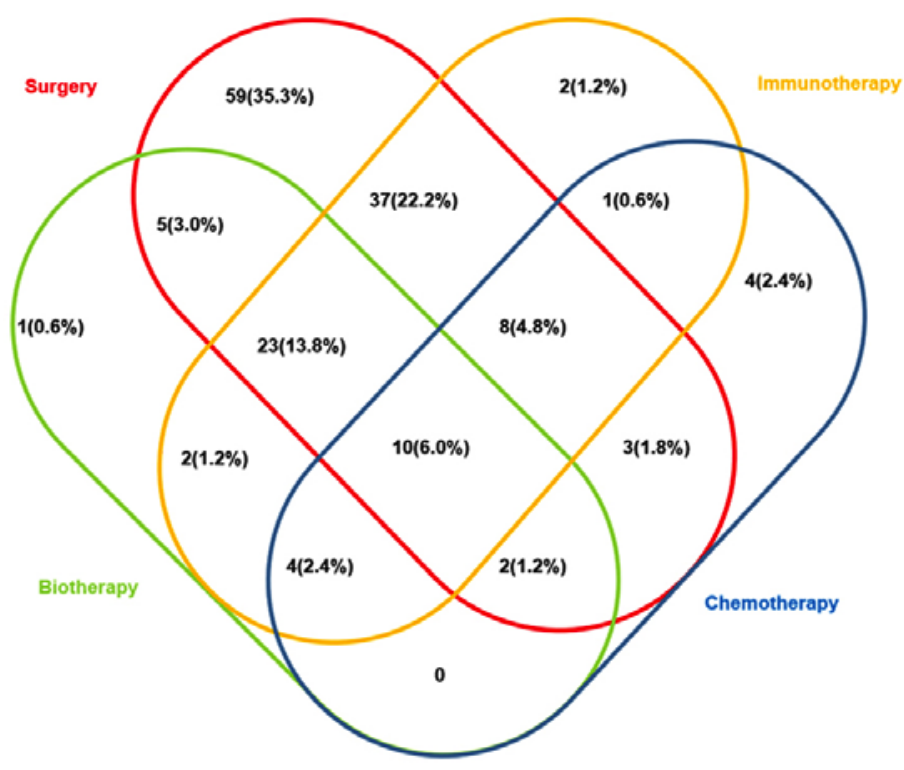

Figure 2. Venn diagram of treatments of patients with MM received in the experimental cohort. MM, malignant melanoma.

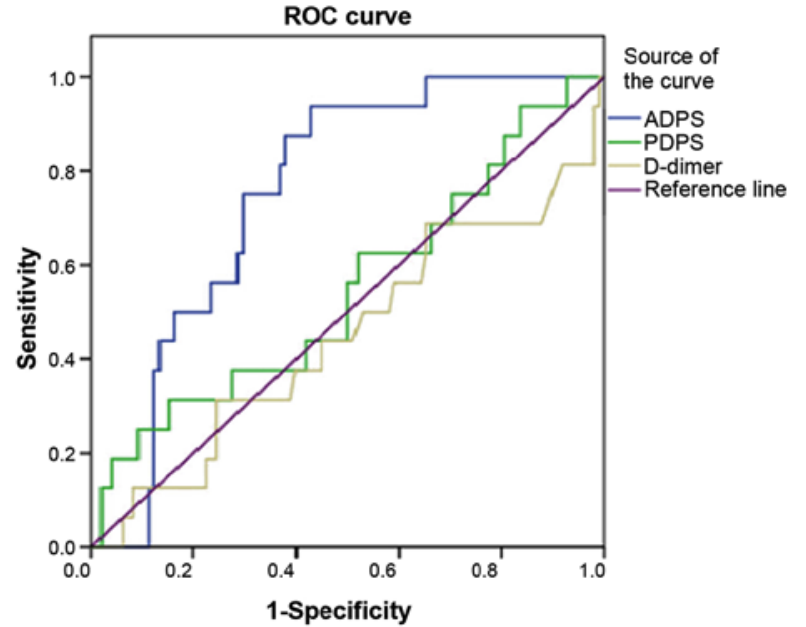

Figure 3. ROC curve of patients with MM in the experimental cohort. ROC, Receiver operating characteristic; MM, malignant melanoma; ADPS, serum albumin/D-dimer prognosis score; PDPS, serum prealbumin/D-dimer prognosis score.

9.4\% accuracy and a Youden index of $16.0 \%$. The AUC for D-dimer was 0.447 . For prediction of metastasis, D-dimer had $31.35 \%$ sensitivity, $75.5 \%$ specificity, $10.6 \%$ accuracy and a Youden index of $6.9 \%$ (Table IV).

Univariate and multivariable Cox regression analyses for metastasis of patients with MM. Univariate Cox regression analyses were performed to screen the potential predictors of metastasis for patients with MM. A total of 9 clinicopathological predictors for overall survival were ascertained through multivariate Cox regression analysis and 3 variables were shown to be independently associated with metastasis; including ADPS Group $[$ hazard ratio $(\mathrm{HR})=8.534 ; 95 \%$ confidence interval $(\mathrm{CI})=$ 3.109-23.425], ulceration $(\mathrm{HR}=4.287$; 95\% $\mathrm{CI}=2.204-8.953)$ and vertical growth phase $(\mathrm{HR}=2.324 ; 95 \% \mathrm{CI}=1.067-5.063)$. In contrast, sex, Breslow thickness, Clark level, histological type, anatomic location and $\mathrm{T}$ stage were not shown to be independent predictors of metastasis (Tables V and VI).

Kaplan-Meier survival analysis of prognostic factors for OS. A 10-year Kaplan-Meier survival analysis was performed and a Log-rank test was used to compare the survival curves of two or more groups. Survival of patients with high ADPS was significantly longer compared with patients with low ADPS. The OS was significantly worse for MM patients with ulcerated melanoma (compared with patients without ulceration; $\mathrm{P}<0.001$; Fig. 4I), MM patients with metastasis (compared with patients without metastasis; $\mathrm{P}<0.001$; Fig. 4J), female patients (compared with male patients; $\mathrm{P}=0.0062$; Fig. 4A), Clark level $>3$ (compared with Clark level 3 and 4; $\mathrm{P}<0.001$; Fig. 4E) and patients with vertical growth phase (compared with radial; $\mathrm{P}<0.001$; Fig. 4G). The Kaplan-Meier survival curves also demonstrated significant difference in distinct TNM stage (multiple comparison; $\mathrm{P}<0.001$; Fig. 4C) and Breslow thickness (multiple comparison; $\mathrm{P}<0.001$; Fig. 4D). The median OS by stage was as follows: T0 stage, 8 months; T1 stage, 108 months; T2 stage, 60 months; T3 stage, 27 months; and T4 stage, 19 months (multiple comparison; $\mathrm{P}<0.001$; Fig. 4B). Median overall survival by histological type was as follows: Acral lentiginous melanoma, 82 months; nodular melanoma, 21 months; superficial spreading melanoma, 74 months; Lentigo malignant melanoma, 50 months; Mucosal melanoma, 47 months; and indeterminate types, 6 months (multiple comparison; $\mathrm{P}<0.001$; Fig. $4 \mathrm{H}$ ). Anatomic region of the $\mathrm{MM}$ was not associated with $\mathrm{OS}$ (multiple comparison; $\mathrm{P}=0.171$; Fig. 4F; Table VII).

Comparison between patients with low and high ADPS. ADPS was calculated for 124 patients. There were 24 patients with low ADPS $(<341.01)$ and 99 patients with high ADPS $(\geq 341.01)$. Patients with high ADPS level were more likely to have a longer OS $(\mathrm{P}=0.016)$, DFS $(\mathrm{P}=0.001)$ and earlier TNM stage (TNM stages I and II) of MM (24.2\% vs. $17.4 \%$; $\mathrm{P}=0.008$ ), whereas these patients were less likely to have an 
Table IV. ROC analysis of metastasis in patients with MM.

\begin{tabular}{lcccccccrr}
\hline & AUC & SE & $\begin{array}{c}\text { Cut off } \\
\text { value }\end{array}$ & $\begin{array}{c}\text { Acurrency } \\
\text { ratio, } \%\end{array}$ & $\begin{array}{c}\text { Sensitivity, } \\
\%\end{array}$ & $\begin{array}{c}\text { Specificity, } \\
\%\end{array}$ & LB & UB & $\begin{array}{r}\text { Youden } \\
\text { index }(\%)\end{array}$ \\
\hline ADPS & 0.773 & 0.045 & 457.38 & 54.60 & 93.8 & 59.6 & 0.686 & 0.861 & 53.40 \\
PDPS & 0.547 & 0.082 & $3,456.61$ & 9.40 & 31.30 & 84.70 & 0.386 & 0.707 & 16.00 \\
D-dimer & 0.447 & 0.084 & 0.238 & 10.60 & 31.35 & 75.50 & 0.282 & 0.611 & 6.85 \\
\hline
\end{tabular}

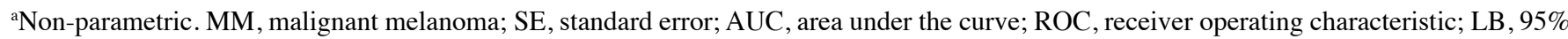
confidence interval lower bound; UB, $95 \%$ confidence interval upper bound.

Table V. Univariate Cox regression analyses of metastasis in patients with MM.

\begin{tabular}{lrcc}
\hline & \multicolumn{3}{c}{ Univariate analysis } \\
\cline { 2 - 4 } Variables & \multicolumn{1}{c}{ HR } & $95 \%$ CI & P-value \\
\hline ADPS group & 13.611 & $6.707-27.622$ & 0.000 \\
Ulceration & 5.257 & $3.036-9.102$ & 0.000 \\
Growth phase & 5.475 & $3.074-9.752$ & 0.000 \\
Sex & -0.580 & $0.339-0.737$ & 0.000 \\
Breslow & 1.749 & $1.415-2.162$ & 0.000 \\
Clark level & 1.507 & $1.261-1.801$ & 0.000 \\
T stage & 1.423 & $1.272-1.592$ & 0.000 \\
Histological type & & & \\
ALM & -0.114 & $0.054-0.242$ & 0.000 \\
NM & -0.556 & $0.273-1.131$ & 0.105 \\
SSM & -0.167 & $0.077-0.361$ & 0.000 \\
LMM & -0.207 & $0.093-0.462$ & 0.000 \\
MCM & -0.226 & $0.104-0.492$ & 0.000 \\
Anatomic region & & & \\
$\quad$ Trunk & -0.311 & $0.142-0.682$ & 0.004 \\
Head/neck & -0.303 & $0.126-0.729$ & 0.008 \\
Extremities & -0.189 & $0.096-0.375$ & 0.000 \\
Mucosal & -0.259 & $0.118-0.568$ & 0.001 \\
\hline
\end{tabular}

ADPS, serum albumin/D-dimer prognosis score; T, tumor; ALM, acral lentiginous melanoma; NM, nodular melanoma; SSM, superficial spreading melanoma; LMM, lentigo malignant melanoma; MCM, mucosal melanoma.

ulcerated melanoma $(19.9 \%$ vs. $20.6 \%$; $\mathrm{P}<0.001)$ or a metastatic melanoma (17.4\% vs. $24.2 \%$; $\mathrm{P}=0.002$; Table VIII).

\section{Discussion}

Due to the low incidence of MM in China there is still no standard approach for diagnosis and treatment, and this is partly due to a lack of reliable indicators of metastasis in the early stages of disease. The aim of the present study was to determine the prognostic value of specific hematological and biochemical parameters routinely assessed at admission to hospital, and their predictive value for prognosis of patients with MM.
Prognostic markers of MM, such as serum LDH, and the identification of new treatment targets including melanogenesis, serve important roles in the treatment and prognosis of MM (9). Melanogenesis is a highly regulated multistep biochemical process of melanin production by melanocytes $(22,23)$. Previous studies have indicated that melanin pigment increases the resistance of melanoma cells to different types of therapy including chemo- or radiotherapy (22). Regarding the role of melanin pigment in chemoresistance of melanoma cells, it was reported that melanogenesis can generate cytotoxic, genotoxic or mutagenic intermediates, which influence tumor microenvironment and tumor immunity (24). Furthermore, studies have shown that melanogenesis reduces OS and DFS in patients with MM (23).

Serum albumin is synthesized in the liver and participates in numerous biological functions in the body, including maintenance of plasma osmotic pressure and regulation of the dynamic balance between tissue fluid and blood vessels $(25,26)$. Serum albumin is also essential for the transport of a number of substances, including hormones, long-chain fatty acids to the liver, unconjugated bilirubin, metals and ions $(27,10)$. Decreases in plasma albumin levels can result in decreased activity of enzymes essential for metabolism of organisms (28). Serum albumin levels can be used to assess nutritional and inflammatory status (28). It has also been demonstrated that malnourished cancer patients often have reduced immune function, poor drug tolerance and poor response to treatments $(12,29)$.

$\mathrm{D}$-dimer is a by-product of fibrinolysis and increases in the levels of D-dimers suggest the presence of coagulation and fibrinolysis (30). Plasma D-dimer levels are useful for monitoring the state of thrombotic diseases and disseminated intravascular coagulation (13). Several studies have shown that the levels of D-dimer are associated with tumor stage, tumor prognosis, lymph node involvement and survival of patients with ovarian cancer (18). In addition, increased D-dimer levels are associated with the degree of malignancy of tumors. Tumor cells or necrotic tissues stimulate the generation and release of coagulation-promoting substances, which activate exogenous coagulation factors resulting in abnormal coagulation and thus activation of the plasminogen activator $(30,31)$. Locally synthesized fibrinolytic enzymes degrade the extracellular matrix and facilitate tumor invasion (14).

In the present study, significant differences in D-dimer levels, ADPS and PDPS were observed in patients with metastasis compared with those without metastasis (Table III). ROC analysis 
Table VI. Multivariate Cox regression analyses of metastasis in patients with MM.

Multivariate analysis

Variables

Coefficient

HR

$95 \% \mathrm{CI}$

P-value

ADPS group

Ulceration

Growth phase

Sex

Breslow

Clark level

T stage

Histological type

Anatomic region

$\begin{array}{rr}2.144 & 8.534 \\ 1.567 & 4.792 \\ 0.843 & 2.324 \\ -0.535 & 0.586 \\ 0.339 & 1.404 \\ 0.047 & 1.048 \\ 0.498 & 1.645 \\ -0.109 & 0.896 \\ 0.035 & 1.035\end{array}$

3.109-23.425

0.000

$2.204-8.953$

0.000

1.067-5.063

0.314-1.092

0.739-2.666

0.820-1.339

0.857-3.158

0.653-1.230

$0.718-1.493$
0.034

0.092

0.300

0.708

0.134

0.498

0.853

MM, malignant melanoma; HR, hazard ratio; CI, confidence interval; ADPS, serum albumin/D-dimer prognosis score; T, tumor; ALM, acral lentiginous melanoma; NM, nodular melanoma; SSM, superficial spreading melanoma; LMM, lentigo malignant melanoma; MCM, mucosal melanoma.
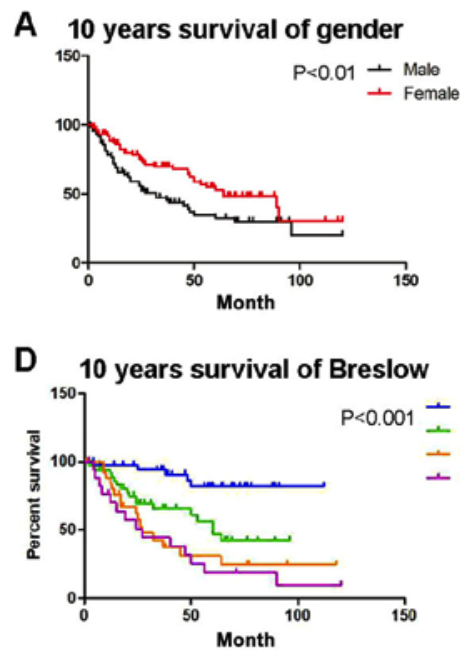

G 10 years survival of growth phase

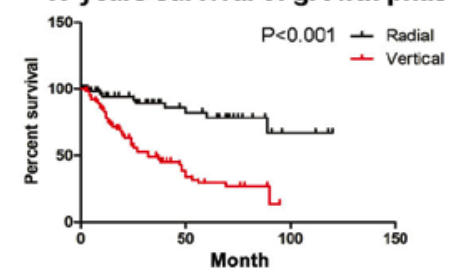

J 10 years survival of metastasis

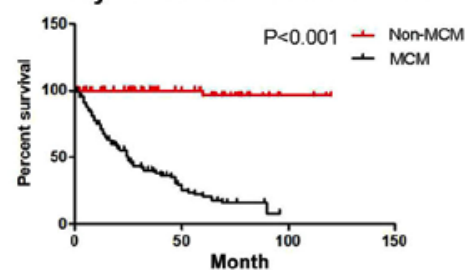

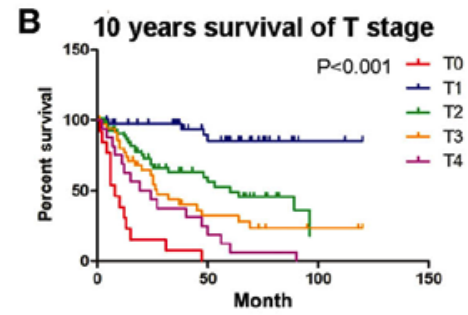

E 10 years survival of Clark level
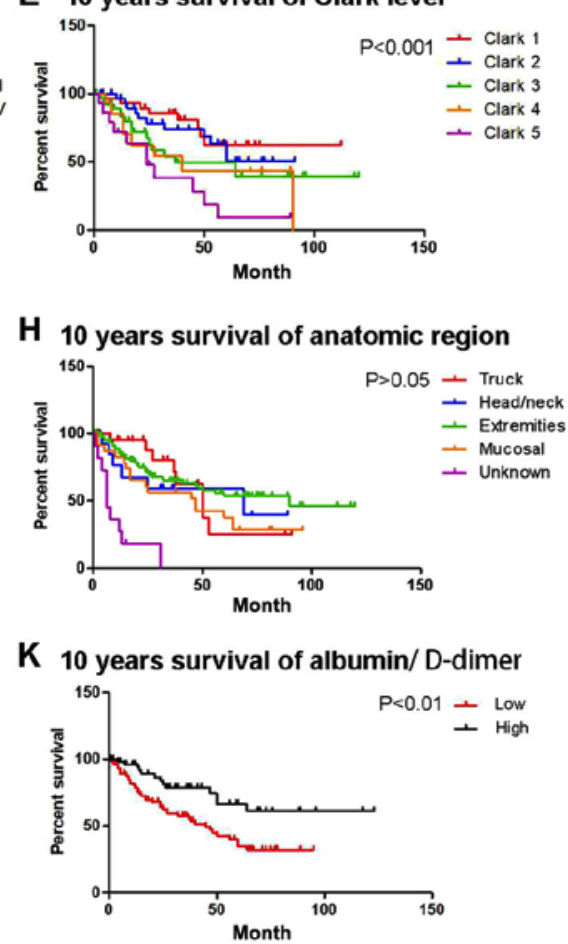

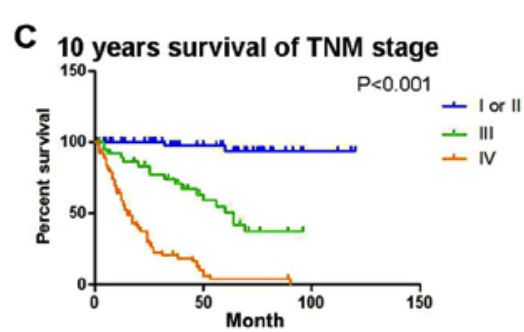

$F^{10}$ years survival of histological type

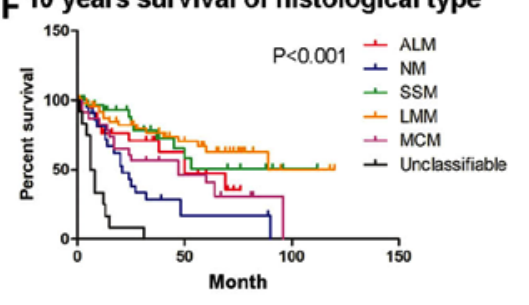

I 10 years survival of ulceration

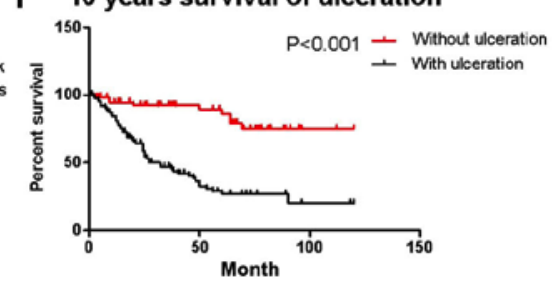

$\mathbf{L}$

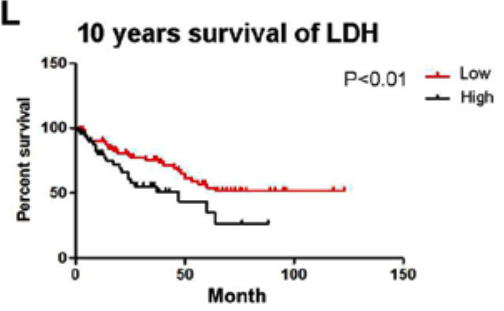

Figure 4. Kaplan-Meier analyses of 10-year OS for the entire cohort of patients according to different stratums by prognostic factors. OS of patients based on (A) sex (P<0.01), (B) T stage (compared with T0, T1, T2, T3 and T4; $\mathrm{P}<0.001$ ), (C) TNM stage (compared with TNM stage I/II, III and IV; P<0.001), (D) Breslow thickness (compared with Breslow I, II, III and IV; P<0.001), (E) Clark level (compared with Clark level 1, 2, 3, 4 and 5; P<0.001), (F) histological type (compared with ALM, NM, SSM, LMM, MCM and unclassifiable; $\mathrm{P}<0.001)$, $(\mathrm{G})$ growth phase $(\mathrm{P}<0.001)$, (H) anatomic region (compared with trunk, head/neck, extremities, mucosal and unknown; $>>0.05)$, (I) ulceration $(\mathrm{P}<0.001)$, (J) metastasis $(\mathrm{P}<0.001)$, (K) albumin/D-dimer $(\mathrm{P}<0.01)$, (L) LDH levels $(\mathrm{P}<0.01)$. OS, overall survival; T, Tumor; TNM, tumor node metastasis; $\mathrm{LDH}$, lactate dehydrogenase; ALM, acral lentiginous melanoma; NM, nodular melanoma; SSM, superficial spreading melanoma; MCM, mucosal melanoma. 
Table VII. Kaplan-Meier survival analysis of prognostic factors for OS.

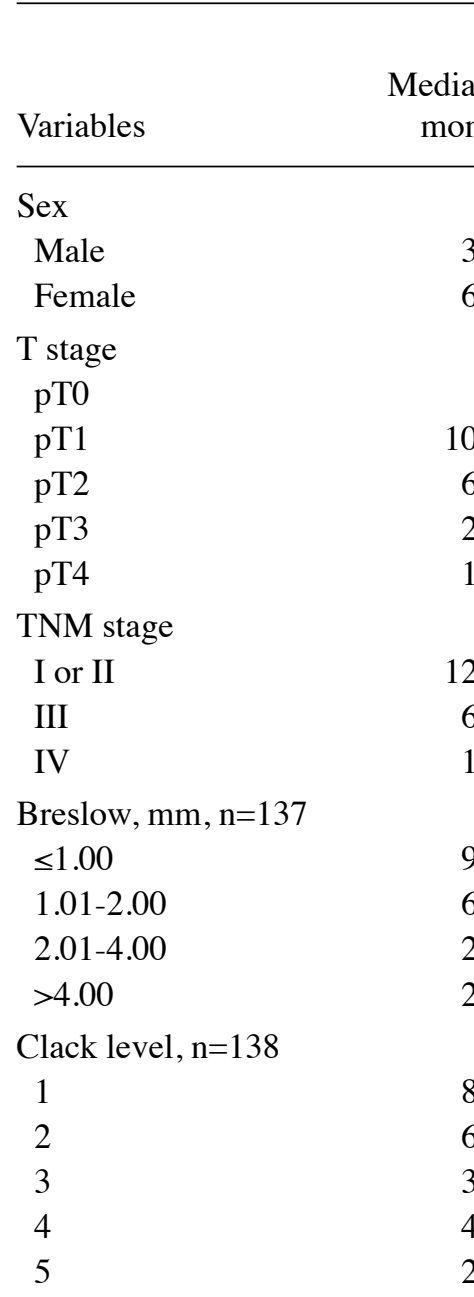

Histological type

$\begin{array}{ll}\text { ALM } & \\ \text { NM } & \\ \text { SSM } & \\ \text { LMM } & 74 \\ \text { MCM } & 50\end{array}$

Unclassifiable

Growth phase

Radial

Vertical

Anatomic region

Trunk

Head/neck

Extremities

Mucosal

Ulceration, $\mathrm{n}=147$

With

Without

Metastasis

With

8

108

60

27

19

120

60

14

98

60

27

24

83

60

37

40

24

82

21

74

50

47

6

$1<0.001^{\mathrm{c}}$

$3 \quad 0.171$

48

69

89

45

79

27

24

Without

113

ADPS group

Low
Table VII. Continued. Kaplan-Meier survival analysis of prognostic factors for OS.

\begin{tabular}{lccc}
\hline Variables & $\begin{array}{c}\text { Median OS, } \\
\text { months }\end{array}$ & df & $\begin{array}{c}\text { Log-rank } \\
\text { analysis, } \\
\text { P value }\end{array}$ \\
\hline $\begin{array}{l}\text { LDH group } \\
\text { Low } \\
\text { High }\end{array}$ & 89 & 1 & $0.010^{\mathrm{a}}$ \\
\hline
\end{tabular}

${ }^{\mathrm{a}} \mathrm{P}<0.05,{ }^{\mathrm{b}} \mathrm{P}<0.01,{ }^{\mathrm{c}} \mathrm{P}<0.001 . \mathrm{n}=167$ unless otherwise specified. OS, overall survival; df, degree of freedom; T, tumor; TMN, tumor node metastasis; ALM, acral lentiginous melanoma; NM, nodular melanoma; SSM, superficial spreading melanoma; LMM, lentigo malignant melanoma; MCM, mucosal melanoma; ADPS, serum albumin/D-dimer prognosis score; LDH, lactate dehydrogenase.

and multivariate Cox regression analysis showed that ADPS was an independent predictor of metastasis for patients with MM. Previous studies reported that albumin and D-dimer served as independent prognostic predictors of prognosis of patients with miliary tuberculosis (32) and the postoperative survival of patients with esophageal squamous cell carcinoma (13). In other studies investigating MM, low serum albumin levels are predictors of morbidity and mortality in patients with MM (33) and elevated D-dimer levels indicated a poor prognosis (32). However, to the best of our knowledge, the present study is the first to show ADPS as an independent predictor of MM metastasis.

In the present study, the highest incidence of MM was observed in individuals aged between $40-70$ years, similar to the reports from other studies with Chinese cohorts (32). Statistical analysis showed ulceration and vertical growth phase were independent risk factors for tumor metastasis in patients with $\mathrm{MM}$ and previous studies have also identified ulceration as an independent prognostic factor in patients with melanoma (34). In certain Chinese studies $>4 \mathrm{~mm}$ tumor thickness and clinical stage III and IV were also found to be significant predictive factors (5).

In the experimental cohort used in the present study, surgery was the most common treatment, followed by surgery combined with immunotherapy, and surgery combined with bioimmunotherapy. To the best of our knowledge, it is unclear if surgery is the best choice to completely remove all lesions in patients with MM with locally advanced or early disease and in patients with distant MM metastasis. However, previous studies have shown that patients with MM with distant metastasis may still benefit from surgery $(35,36)$. Patients with stage IV MM are usually treated with systemic biologics and/or chemotherapy; however, treatment for patients with metastatic MM has been a challenge as aggressive treatments, including combination of immunotherapy with other therapies, have failed to show satisfactory efficacy $(37,38)$.

The cohort of the present study was compared with the cohort of patients with MM in cBioPortal and significant differences were found, including differences in OS, DFS, age at diagnosis and anatomic locations of metastasis between the two groups of patients. There may be several reasons for these differences, for example the sample size of the experimental cohort in the present study was small, and Caucasians comprised a majority 
Table VIII. Comparison between patients with high ADPS level and low ADPS.

\begin{tabular}{|c|c|c|c|}
\hline & Low ADPS level & High ADPS level & P-value \\
\hline $\mathrm{OS}^{\mathrm{c}}$, mean $\pm \mathrm{SD}$ & $26.96 \pm 23.67$ & $41.34 \pm 30.65$ & 0.139 \\
\hline $\mathrm{DFS}^{\mathrm{c}}$, mean $\pm \mathrm{SD}$ & $15.46 \pm 17.13$ & $34.88 \pm 26.03$ & 0.733 \\
\hline TNM stage $^{\mathrm{d}}, \mathrm{n}(\%)$ & & & 1.000 \\
\hline I or II & $25(18.9 \%)$ & $32(24.2 \%)$ & \\
\hline III & $20(15.2 \%)$ & $12(9.1 \%)$ & \\
\hline IV & $32(24.2 \%)$ & $11(8.3 \%)$ & \\
\hline $\operatorname{Sex}^{\mathrm{d}}, \mathrm{n}(\%)$ & & & 0.644 \\
\hline Male & $30(25.6 \%)$ & $21(17.9 \%)$ & \\
\hline Female & $36(56.4 \%)$ & $30(25.6 \%)$ & \\
\hline Breslow $^{\mathrm{d}}$ & & & 0.335 \\
\hline$\leq 1.00$ & $20(17.1 \%)$ & $17(14.5 \%)$ & \\
\hline $1.01-2.00$ & $19(16.2 \%)$ & $21(17.9 \%)$ & \\
\hline $2.01-4.00$ & $16(13.7 \%)$ & $8(6.8 \%)$ & \\
\hline$>4.00$ & $11(9.4 \%)$ & $5(4.3 \%)$ & \\
\hline Clark level $^{\mathrm{d}}$ & & & 0.713 \\
\hline 1 & $18(14.9 \%)$ & $9(7.4 \%)$ & \\
\hline 2 & $15(12.4 \%)$ & $15(12.4 \%)$ & \\
\hline 3 & $17(14.0 \%)$ & $16(13.2 \%)$ & \\
\hline 4 & $7(5.8 \%)$ & $6(5.0 \%)$ & \\
\hline 5 & $9(7.4 \%)$ & $9(7.4 \%)$ & \\
\hline Anatomic region $^{\mathrm{d}}$ & & & 0.132 \\
\hline Truck & $16(10.9 \%)$ & $5(3.4 \%)$ & \\
\hline Head/neck & $10(6.8 \%)$ & $4(2.7 \%)$ & \\
\hline Extremities & $51(34.7 \%)$ & $47(32.0 \%)$ & \\
\hline Mucosal & $7(4.8 \%)$ & $7(4.8 \%)$ & \\
\hline Ulceration $^{\mathrm{d}}$ & & & $0.001^{\mathrm{a}}$ \\
\hline With & $68(51.9 \%)$ & $26(19.9 \%)$ & \\
\hline Without & $10(7.6 \%)$ & $27(20.6 \%)$ & \\
\hline Metastasis $^{\mathrm{d}}$ & & & $0.002^{\mathrm{b}}$ \\
\hline With & $53(40.2 \%)$ & $23(17.4 \%)$ & \\
\hline Without & $24(18.2 \%)$ & $24(18.2 \%)$ & \\
\hline T stage ${ }^{d}$ & & & 0.706 \\
\hline pT0 & $4(3.0 \%)$ & 0 & \\
\hline pT1 & $21(15.9 \%)$ & $16(12.1 \%)$ & \\
\hline pT2 & $22(16.6 \%)$ & $23(17.4 \%)$ & \\
\hline pT3 & $19(14.4 \%)$ & $11(8.3 \%)$ & \\
\hline pT4 & $11(8.3 \%)$ & $5(11.0 \%)$ & \\
\hline Histological type ${ }^{\mathrm{d}}$ & & & 0.294 \\
\hline ALM & $26(22.2 \%)$ & $16(13.7 \%)$ & \\
\hline NM & $1(0.8 \%)$ & $6(5.1 \%)$ & \\
\hline SSM & $15(12.8 \%)$ & $14(12.0 \%)$ & \\
\hline LMM & $6(5.1 \%)$ & $13(11.1 \%)$ & \\
\hline MCM & $11(9.4 \%)$ & $6(5.1 \%)$ & \\
\hline Unclassifiable & $3(2.7 \%)$ & 0 & \\
\hline Growth phase $^{\mathrm{d}}$ & & & 0.065 \\
\hline Radial & $22(19.8 \%)$ & $26(23.4 \%)$ & \\
\hline Vertical & $40(36.0 \%)$ & $23(20.7 \%)$ & \\
\hline
\end{tabular}

${ }^{\mathrm{a}} \mathrm{P}<0.001,{ }^{\mathrm{b}} \mathrm{P}<0.01,{ }^{\mathrm{c}} \mathrm{P}$-value based on t-test. ${ }^{\mathrm{d}} \mathrm{P}$-value based on $\chi^{2}$ test. $\mathrm{SD}$, standard deviation; ADPS, serum albumin/D-dimer prognosis score; OS, overall survival; DFS, disease free survival; TNM, tumor node metastasis; T, tumor; ALM, acral lentiginous melanoma; NM, nodular melanoma; SSM, superficial spreading melanoma; LMM, lentigo malignant melanoma; MCM, mucosal melanoma. 
of the patients in the cBioPortal cohort, whereas all the patients in the present study were Chinese. Melanoma is more common in light-skinned individuals, as individuals lacking protective melanin pigments are more susceptible to cutaneous melanoma compared with darker-skinned individuals (22). Therefore lower quantities of protective melanin pigment may increase the susceptibility of Caucasians to damage caused by ultraviolet radiation $(22,24)$. Previous epidemiological and experimental data have indicated that ultraviolet light, through its mutagenic activity, is the most likely cause of cutaneous melanoma in Caucasian patients (39). MM in Caucasian patients also predominantly occurs on the trunk and the most common type is the superficial spreading type (40); however, in Chinese patients, MM occurs most frequently on the extremities or the mucosa (41). Moreover, the majority of Caucasian patients are diagnosed at stage I (20), whereas the majority of Chinese patients are diagnosed at stage II or III (41). The reasons for these ethnic differences should be a focus of future studies.

The present study has certain limitations. First, the sample size was small, and all patients were recruited from a single institution. However, the First Affiliated Hospital of Zhengzhou University is a major referral center for MM treatment in central China, and the study population can be considered representative of this region. Second, some patients were lost to follow-up as a number of patients failed to comply with regular follow-up due to economic reasons or lack of awareness.

Overall, there are significant differences between patients with MM from central China and those from other parts of the world. ADPS may be a useful predictor of MM metastasis in the early stages of disease.

\section{Acknowledgements}

Not applicable.

\section{Funding}

The present study was supported by grants from Science and Technology Project of Henan (grant no. 182102310085) and the Scientific Research Team Construction Foundation of Henan Province (grant no. TD2011010).

\section{Availability of data and materials}

The datasets used or analyzed during the present study are available from the corresponding author on reasonable request.

\section{Authors' contributions}

GSL and LBL designed the study. KS analyzed and interpreted the patient data, and was a major contributor in writing the manuscript. XRZ, ZYL, NS, LSG and YW analyzed and interpreted the patient data. XC, ZWZ, BHX and SXY performed the histological examination of the samples. All authors read and approved the final manuscript.

\section{Ethics approval and consent to participate}

The study was approved by The Ethics Committee of the First Affiliated Hospital of Zhengzhou University (Zhengzhou,
China). Written informed consent was obtained from all individual participants included in the study. The trial registration no. is 2018-LW-037 and this clinical trial was registered in the First Affiliated Hospital of Zhengzhou University Clinical Trial Registry in March 2018.

\section{Patient consent for publication}

Not applicable.

\section{Competing interests}

The authors declare that they have no competing interests.

\section{References}

1. Gershenwald JE, Scolyer RA, Hess KR, Sondak VK, Long GV, Ross MI, Lazar AJ, Faries MB, Kirkwood JM, McArthur GA, et al: Melanoma staging: Evidence-based changes in the American joint committee on cancer eighth edition cancer staging manual. CA Cancer J Clin 67: 472-492, 2017.

2. Gao J, Aksoy BA, Dogrusoz U, Dresdner G, Gross B, Sumer SO, Sun Y, Jacobsen A, Sinha R, Larsson E, et al: Integrative analysis of complex cancer genomics and clinical profiles using the cBioPortal. Sci Signal 6: 1, 2013.

3. Thompson JF, Soong SJ, Balch CM, Gershenwald JE, Ding S, Coit DG, Flaherty KT, Gimotty PA, Johnson T, Johnson MM, et al: Prognostic significance of mitotic rate in localized primary cutaneous melanoma: An analysis of patients in the multi-institutional American joint committee on cancer melanoma staging database. J Clin Oncol 29: 2199-2205, 2011.

4. Temam S, Mamelle G, Marandas P, Wibault P, Avril MF, Janot F, Julieron M, Schwaab G and Luboinski B: Postoperative radiotherapy for primary mucosal melanoma of the head and neck. Cancer 103: 313-319, 2005.

5. Yu J, Luo X, Huang H, Zhai Z, Shen Z and Lin H: Clinical characteristics of malignant melanoma in southwest China: A single-center series of 82 consecutive cases and a meta-analysis of 958 reported cases. PLoS One 11: e0165591, 2016.

6. Shoo BA and Kashani-Sabet M: Melanoma arising in African-, Asian-, Latino- and Native-American populations. Semin Cutan Med Surg 28: 96-102, 2009.

7. Hao M, Zhao G, Du X, Yang Y and Yang J: Clinical characteristics and prognostic indicators for metastatic melanoma: Data from 446 patients in north China. Tumor Biol 37: 10339-10348, 2016.

8. Iacono D, Basile D, Gerratana L, Vitale MG, Pelizzari G, Cinausero M, Poletto E, Puglisi F, Fasola G and Minisini AM: Prognostic role of disease extent and lymphocyte-monocyte ratio in advanced melanoma. Melanoma Res 29: 510-515, 2019.

9. Daneshmandi S, Wegiel B and Seth P: Blockade of lactate dehydrogenase-a (LDH-A) improves efficacy of anti-programmed cell death-1 (PD-1) therapy in melanoma. Cancers (Basel) 11: E450, 2019.

10. Fanali G, di Masi A, Trezza V, Marino M, Fasano M and Ascenzi P: Human serum albumin: From bench to bedside. Mol Aspects Med 33: 209-290, 2012.

11. Mittman N, Avram MM, Oo KK, Chattopadhyay J: Prealbumin as an important predictor for survival and nutritional status in hemodialysis and peritoneal dialysis patients. In: Improving Prognosis for Kidney Disorders. Avram MM (ed). Springer, Dordrecht, pp61-67, 2002.

12. Fan L, Wang X, Chi C, Wang Y, Cai W, Shao X, Xu F, Pan J, Zhu Y, Shangguan X, et al: Prognostic nutritional index predicts initial response to treatment and prognosis in metastatic castration-resistant prostate cancer patients treated with abiraterone. Prostate 77: 1233-1241, 2017.

13. Liu DQ, Li FF and Jia WH: Cumulative scores based on plasma D-dimer and serum albumin levels predict survival in esophageal squamous cell carcinoma patients treated with transthoracic esophagectomy. Chin J Cancer 35: 11, 2016.

14. Diao D, Wang Z, Cheng Y, Zhang H, Guo Q, Song Y, Zhu K, Li K, Liu D and Dang C: D-dimer: Not just an indicator of venous thrombosis but a predictor of asymptomatic hematogenous metastasis in gastric cancer patients. PLoS One 9: e101125, 2014. 
15. Batschauer AP, Figueiredo CP, Bueno EC, Ribeiro MA Dusse LM, Fernandes AP, Gomes KB and Carvalho MG: D-dimer as a possible prognostic marker of operable hormone receptor-negative breast cancer. Ann Oncol 21: 1267-1272, 2010.

16. Kilic M, Yoldas O, Keskek M, Ertan T, Tez M, Gocmen E and Koc M: Prognostic value of plasma D-dimer levels in patients with colorectal cancer. Colorectal Dis 10: 238-241, 2008.

17. Altiay G, Ciftci A, Demir M, Kocak Z, Sut N, Tabakoglu E, Hatipoglu ON and Caglar T: High plasma D-dimer level is associated with decreased survival in patients with lung cancer. Clin Oncol (R Coll Radiol) 19: 494-498, 2007.

18. Mirshahi SS, Pujade-Lauraine E, Soria C, Mirshahi M, Fretault J, Bernadou A and Soria J: D-dimer and CA-125 levels in patients with ovarian cancer during antineoplastic therapy. Prognostic significance for the success of anti-cancer treatment. Cancer 69: 2289-2292, 1992.

19. Ferrucci PF, Gandini S, Battaglia A, Alfieri S, Di Giacomo AM Giannarelli D, Cappellini GC, De Galitiis F, Marchetti P, Amato G, et al: Baseline neutrophil-to-lymphocyte ratio is associated with outcome of ipilimumab-treated metastatic melanoma patients. Br J Cancer 112: 1904-1910, 2015.

20. Schuurman MS, de Waal AC, Thijs EJM, van Rossum MM Kiemeney LALM and Aben KKH: Risk factors for second primary melanoma among Dutch patients with melanoma. Br J Dermatol 176: 971-978, 2017

21. Cerami E, Gao J, Dogrusoz U, Gross BE, Sumer SO, Aksoy BA, Jacobsen A, Byrne CJ, Heuer ML, Larsson E, et al: The cBio cancer genomics portal: An open platform for exploring multidimensional cancer genomics data. Cancer Discov 2: 401-404, 2012

22. Brożyna AA,Jóźwicki W,Roszkowski K,Filipiak J and Slominski AT: Melanin content in melanoma metastases affects the outcome of radiotherapy. Oncotarget 7: 17844-17853, 2016.

23. Brozyna AA, Jozwicki W, Carlson JA and Slominski AT: Melanogenesis affects overall and disease-free survival in patients with stage III and IV melanoma. Hum Pathol 44 2071-2074, 2013

24. Slominski A, Kim TK, Brożyna AA, Janjetovic Z, Brooks DL, Schwab LP, Skobowiat C, Jóźwicki W and Seagroves TN: The role of melanogenesis in regulation of melanoma behavior: Melanogenesis leads to stimulation of HIF-1 $\alpha$ expression and HIF-dependent attendant pathways. Arch Biochem Biophys 563: 79-93, 2014

25. Gatta A, Verardo A and Bolognesi M: Hypoalbuminemia. Intern Emerg Med 7 (Suppl 3): 193-199, 2012.

26. Moujaess E, Fakhoury M, Assi T, Elias H, El Karak F, Ghosn M and Kattan J: The Therapeutic use of human albumin in cancer patients' management. Crit Rev Oncol Hematol 120: 203-209, 2017.

27. Li S, Xu H, Wu C, Wang W, Jin W, Gao H, Li H, Zhang S, Xu J, Zhang W, et al: Prognostic value of $\gamma$-glutamyltransferase-to-al bumin ratio in patients with pancreatic ductal adenocarcinoma following radical surgery. Cancer Med 8: 572-584, 2019.

28. Matsuda S, Takeuchi H, Kawakubo H, Fukuda K, Nakamura R, Takahashi T, Wada N, Saikawa Y, Omori T and Kitagawa Y: Cumulative prognostic scores based on plasma fibrinogen and serum albumin levels in esophageal cancer patients treated with transthoracic esophagectomy: Comparison with the glasgow prognostic score. Ann Surg Oncol 22: 302-310, 2015.

29. Forrest LM, Mcmillan DC, Mcardle CS, Angerson WJ and Dunlop DJ: Comparison of an inflammation-based prognostic score (GPS) with performance status (ECOG) in patients receiving platinum-based chemotherapy for inoperable non-small-cell lung cancer. Br J Cancer 90: 1704-1706, 2004.

30. Desch A, Gebhardt C, Utikal J and Schneider SW: D-dimers in malignant melanoma: Association with prognosis and dynamic variation in disease progress. Int J Cancer 140: 914-921, 2017.

31. Kwon HC, Oh SY, Lee S, Kim SH, Han JY, Koh RY, Kim MC and Kim HJ: Plasma levels of prothrombin fragment F1+2, D-dimer and prothrombin time correlate with clinical stage and lymph node metastasis in operable gastric cancer patients. Jpn J Clin Oncol 38: 2-7, 2008

32. Deng W, Yu M, Ma H, Hu LA, Chen G, Wang Y, Deng J, Li C, Tong J and Wang DX: Predictors and outcome of patients with acute respiratory distress syndrome caused by miliary tuberculosis: A retrospective study in Chongqing, China. BMC Infect Dise 12: 121, 2012

33. Datta M, Savage P, Lovato J and Schwartz GG: Serum calcium, albumin and tumor stage in cutaneous malignant melanoma. Future Oncol 12: 2205-2214, 2016

34. Zhang $\mathrm{M}$ and Zhang $\mathrm{N}$ : Clinical and prognostic factors in 98 patients with malignant melanoma in China. J Int Med Res 45: 1369-1377, 2017.

35. Raigani S, Cohen $\mathrm{S}$ and Boland GM: The role of surgery for melanoma in an era of effective systemic therapy. Curr Oncol Rep 19: 17, 2017.
36. Saranga-Perry V, Ambe C, Zager JS and Kudchadkar RR: Recent developments in the medical and surgical treatment of melanoma. Ca Cancer J Clin 64: 172-185, 2014

37. Flaherty KT, Puzanov I, Kim KB, Ribas A, McArthur GA, Sosman JA, O'Dwyer PJ, Lee RJ, Grippo JF, Nolop K and Chapman PB: Inhibition of mutated, activated BRAF in metastatic melanoma. N Engl J Med 363: 809-819, 2010.

38. Nestle FO, Alijagic S, Gilliet M, Sun Y, Grabbe S, Dummer R, Burg G and Schadendorf D: Vaccination of melanoma patients with peptideor tumor lysate-pulsed dendritic cells. Nat Med 4: 328-332, 1998.

39. Slominski AT and Carlson JA: Melanoma resistance: A bright future for academicians and a challenge for patient advocates. Mayo Clinic Proc 89: 429-433, 2014.

40. Huang K, Xu Y, Joseph R, Bagaria SP, Misra S and Chen Y: Comparative analysis of acral melanoma in Chinese and caucasian patients. Ann Surg Oncol 26: S158-S159, 2019.

41. Huang YS, Chen XX, Yang SX, Wu LS, Zhao JY, Li XY, Tu P and $\mathrm{Li} \mathrm{H}$ : Preliminary exploration of the clinical features of Chinese patients with skin malignancies and premalignancies: A retrospective study of 1420 cases from peking university first hospital. J Eur Acad Dermatol Venereol 27: 1114-1119, 2013.

42. Taylor AM, Shih J, Ha G, Gao GF, Zhang X, Berger AC, Schumacher SE, Wang C, Hu H, Liu J, et al: Genomic and functional approaches to understanding cancer aneuploidy. Cancer Cell 33: 676-689.e673, 2018.

43. Sanchez-Vega F, Mina M, Armenia J, Chatila WK, Luna A, La KC, Dimitriadoy S, Liu DL, Kantheti HS, Saghafinia S, et al: Oncogenic signaling pathways in the cancer genome atlas. Cell 173: 321-337.e310, 2018.

44. Liu J, Lichtenberg T, Hoadley KA, Poisson LM, Lazar AJ, Cherniack AD, Kovatich AJ, Benz CC, Levine DA, Lee AV, et al: An integrated TCGA pan-cancer clinical data resource to drive high-quality survival outcome analytics. Cell 173: 400-416.e411, 2018.

45. Hoadley KA, Yau C, Hinoue T, Wolf DM, Lazar AJ, Drill E, Shen R, Taylor AM, Cherniack AD, Thorsson V, et al: Cell-of-origin patterns dominate the molecular classification of 10,000 tumors from 33 types of cancer. Cell 173: 291-304.e296, 2018.

46. Gao Q, Liang WW, Foltz SM, Mutharasu G, Jayasinghe RG, Cao S, Liao WW, Reynolds SM, Wyczalkowski MA, Yao L, et al: Driver fusions and their implications in the development and treatment of human cancers. Cell Rep 23: 227-238.e223, 2018

47. Ellrott K, Bailey MH, Saksena G, Covington KR, Kandoth C, Stewart C, Hess J, Ma S, Chiotti KE, McLellan M, et al: Scalable open science approach for mutation calling of tumor exomes using multiple genomic pipelines. Cell Syst 6: 271-281.e277, 2018.

48. Liang WS, Hendricks W, Kiefer J, Schmidt J, Sekar S, Carpten J, Craig DW, Adkins J, Cuyugan L, Manojlovic Z, et al: Integrated genomic analyses reveal frequent TERT aberrations in acral melanoma. Genome Res 27: 524-532, 2017.

49. Berger MF, Hodis E, Heffernan TP, Deribe YL, Lawrence MS, Protopopov A, Ivanova E, Watson IR, Nickerson E, Ghosh P, et al: Melanoma genome sequencing reveals frequent PREX2 mutations. Nature 485: 502-506, 2012.

50. Hodis E, Watson IR, Kryukov GV, Arold ST, Imielinski M, Theurillat JP, Nickerson E, Auclair D, Li L, Place C, et al: A landscape of driver mutations in melanoma. Cell 150: 251-263, 2012.

51. Krauthammer M, Kong Y, Ha BH, Evans P, Bacchiocchi A, McCusker JP, Cheng E, Davis MJ, Goh G, Choi M, et al: Exome sequencing identifies recurrent somatic RAC1 mutations in melanoma. Nat Genetics 44: 1006-1014, 2012.

52. Van Allen EM, Wagle N, Sucker A, Treacy DJ, Johannessen CM, Goetz EM, Place CS, Taylor-Weiner A, Whittaker S, Kryukov GV, et al: The genetic landscape of clinical resistance to RAF inhibition in metastatic melanoma. Cancer Discov 4: 94-109, 2014.

53. Hugo W,Zaretsky JM,Sun L, Song C,Moreno BH,Hu-Lieskovan S, Berent-Maoz B, Pang J, Chmielowski B, Cherry G, et al: Genomic and transcriptomic features of response to anti-PD-1 therapy in metastatic melanoma. Cell 165: 35-44, 2016.

54. Shain AH, Garrido M, Botton T, Talevich E, Yeh I, Sanborn JZ, Chung J, Wang NJ, Kakavand H, Mann GJ, et al: Exome sequencing of desmoplastic melanoma identifies recurrent NFKBIE promoter mutations and diverse activating mutations in the MAPK pathway. Nat Genetics 47: 1194-1199, 2015.

This work is licensed under a Creative Commons Attribution-NonCommercial-NoDerivatives 4.0 International (CC BY-NC-ND 4.0) License. 